\title{
Alfred Wallace's Echoes in the Amazon
}

\author{
Geraldo Mendes dos Santos ${ }^{1, *}$ \\ ${ }^{1}$ National Research Institute of Amazon (INPA), Manaus, AM. Brasil \\ *Correspondence: Biologist, Philopher, Researcher of National Research Institute of Amazon (INPA), Manaus, AM. \\ Brasil. Tel: 055-92-981-544-959. E-mail: gsantos@inpa.gov.br
}

Received: December 29, 2018 Accepted: January 17, 2019 Online Published: January 20, 2019

doi:10.5430/wjss.v6n1p15 URL: https://doi.org/10.5430/wjss.v6n1p15

\begin{abstract}
This article deals with some aspects of Alfred Russel Wallace's historic journey to the Amazon between 1848 and 1852. In it are highlighted the impressions that this naturalist has pointed out about the region, cities, indigenous customs and especially about fish of the Black River. More objectively, the article discusses the reasons for the trip, the two trips to the Uaupés River, and the strategic visions Wallace presented about food production in that distant region. At the end is outlined a profile of the personality of this famous traveler and the lessons he left to posterity, especially to the young naturalists and scientists.
\end{abstract}

Keywords:

\section{Introduction}

Alfred Wallace was an eminent naturalist who was in the Amazon between 1848 and 1852, getting to know landscapes and cultures and collecting biological and craft material to meet the demands of museums and collectors of the old world. He also went to find evidence about the origin of varieties and species, a central issue that stirred the scientific and social milieu of his time.

Upon arriving in the Amazon, Wallace was 25 years old, a young man fresh out of adolescence in chronological terms, but a mature adult in terms of autonomy and intellectual courage. What he faced, did and interpreted from the Amazon in the four years he was there is enviable and the height of the great scientists of the world.

Wallace's experiences and ideas first launched in his diaries and later enhanced in his books, continue to resonate to the present and will certainly continue to do so in the future, for that is what characterizes good science and the figure of great thinkers.

The present article deals with some aspects of Wallace 's trip, notably his observations on the cities, the indigenous customs and, above all, the fish of the Negro River. The objective is to continue extolling the figure of this prominent naturalist and confronting his data and ideas in the light of new understandings about the Amazon. In this sense, it is about expanding the ideals that Wallace left behind in this region and that continue to resonate in the minds and hearts of the present generation, especially among young naturalists and scientists.

\section{Reasons for the Amazon Trip}

The first questioning about Wallace's trip to the Amazon is precisely about the reason for his accomplishment; that is, to know the reasons or justifications that led him, still in his prime, to undertake such a long, complex and risky journey to a region almost totally isolated and unknown.

Part of this questioning is clarified by Wallace himself in the preface to the first edition of the book he wrote about this trip; says the great motive was the "ardent desire to visit a tropical region, to contemplate the exuberance of animal and plant life that was said to exist there; and also to see, with my own eyes, all the wonders, whose knowledge, through the reading of travelers' narratives, delighted me so much. He then clarifies what are the reasons that lead him to define professional goals and family ties and from an extended period of time to infinity. It is important to clarify that the term is not extended, but instead, a tropical place, marked by a lot of heat, humidity and rain; and very place very rich in biodiversity. 
Wallace also points out that his collections of animals, plants and other natural elements from the Amazon would be sold in Europe to cover his travel and collection expenses, but that the most important thing was "the pleasure in contemplating so many beautiful and extraordinary things with which he continually I found myself, allied to the deep interest that I was beginning to feel from the in-situ study of the various human races". This sentence shows that, besides the fauna and flora, this young naturalist was also interested in aspects related to indigenous culture.

\section{Arrival in the Amazon (Belém)}

Wallace tells in a marvelous way his arrival in Belém, accompanied by his colleague Henri Bate: "It was on the morning of May 26, 1848, that after a quick 29-day journey from Liverpool, we anchored in front of the southern bar of the Amazonas and we had our first view of the South American lands. [...]; we anchored again on the 28th, at dawn, and when the sun was born in a cloudless sky, we saw the city of Para (Belém), surrounded by the dense forest; the crowns of palm trees and banana trees stood out above all others".

"Our eyes rejoice doubly at the beautiful sight of these plants in their natural state; which we so often admire in the greenhouses of Kew and Chatsworth. The canoes that passed with their variegated crew composed of blacks and Indians; the vultures that hovered above our heads or that lazily walked along the beach; the flocks of swallows that lay on the roofs of churches and houses; everything served to occupy our attention; finally came the customs officials and the permission to descend on land".

Soon after this beautiful description, Wallace points out that Belém owns only 15,000 inhabitants, despite being the largest city on the edge of the largest river in the world, the Amazon and being the capital of a Province (Grão Pará) whose area was equal to the whole of Western Europe. It also highlights the fact that there resides a President, appointed by the Emperor of Brazil and a Bishop whose diocese extended inland for about two thousand miles, through a territory populated by countless tribes of Indians not yet catechized. Moreover, it was admired for being this, the richest Province and also the least known of the vast Empire.

Wallace and Bates spent more than a year and a half in the outskirts of Belém to learn the language, to interact with native culture, to keep in touch with their countrymen and to collect insects and other animals on the island of Marajó, mouth of the Tocantins River, the lower Pará River and the Amazon River estuary. After that, Bates stays and Wallace climbs the Amazon River, bound for Manaus and thence to the Rio Negro.

\section{Arrived in Manaus}

After a few days of travel, Wallace brings in Manaus, exactly on the last day of the year 1849; in fact, he contributes in Barra do Rio Negro, the name given to this village at that time. On the first night he arrived, he went fishing, and the next morning he noticed that the river's water looked like black paint when seen on the riverbed, but "gleamed with gold glitter when seen on the white sands of its banks." He emphasizes that the water had a pale brown color, as you can see by placing it in a glass.

The observation about the strong color difference between the waters of the Tocantins, Amazonas and Negro rivers was a striking fact, because years later and until today, this has been the fundamental classification for the waters of the Amazon.

As in Belém, Wallace spent several months observing and collecting on the outskirts of Manaus,also preparing the material and recruiting auxiliaries to undertake a long and time-consuming journey to the upper reaches of the Negro River and its great tributary, the Uaupes River.

According to Wallace, Manaus was nothing more than a small village with five to six thousand people, composed mostly of Indians and half-breeds; "it was quite probable that there was not a single person among those born in this village who had entirely European blood, such was the miscegenation between the Portuguese and the Indians".

In that village lost in the middle of the forest, the exported products consisted mainly of Brazil nuts, sarsaparilla and fish. In exchange, she imported inferior cotton fabrics from Europe, in addition to large quantities of knives, beads, mirrors, and other trinkets used in trade with the Indians who make this city their general store.

Wallace claims that the more civilized residents of Barra were engaged in trade, arguing that they knew of no diversions other than drinking and gambling, although they did so on a small scale; most of them never opened a book and were unaware of any kind of intellectual occupation.

As might be expected in these circumstances, one of his major concerns was fashion; "on Sundays, at mass, everyone 
dressed in style; the women appeared very elegant, in a multicolored parade of fragrances and muslin; her beautiful wigs were neatly arranged and adorned with flowers. Beside him, the gentlemen who stayed in their filthy department store in their sleeves and slippers for the week were now dressed in black suits, felt hat, satin ties, and short-billed patent leather boots. After mass, it was time for ceremonial visits, when people went from house to house and kept commenting on the scandals that had accumulated during the week".

\section{First Trip to Rio Negro}

After eight months of his arrival in Manaus, Wallace began his long-desired trip to the upper Rio Negro on board a canoe about $11 \mathrm{~m}$ long by $2 \mathrm{~m}$ wide, a prow covered with palm fronds and paddled by indigenous arms. As he was in no hurry and wanted to take advantage of all the facts of nature and culture, he traveled quietly down the Rio Negro, noting everything he saw and heard; mapping the river; collecting and preserving animals and palm trees; observing landscapes and customs and negotiating with indigenous people.

About seven months after the departure of Manaus, he arrives at the most extreme point of this river in Brazilian territory; from there it advances to the village of Yavita, in Venezuelan lands. He had been in this small village for over a month, early in 1851, and there was something he might have never done before, and possibly never would have: a poetry. In it, he describes what he had been thinking and feeling in that quiet and distant region of the world considered as civilized.

\section{First Trip to Rio Negro}

After eight months of his arrival in Manaus, Wallace began his long-desired trip to the upper Rio Negro on board a canoe about $11 \mathrm{~m}$ long by $2 \mathrm{~m}$ wide, a prow covered with palm fronds and paddled by indigenous arms. As he was in no hurry and wanted to take advantage of all the facts of nature and culture, he traveled quietly down the Rio Negro, noting everything he saw and heard; mapping the river; collecting and preserving animals and palm trees; observing landscapes and customs and negotiating with indigenous people.

About seven months after the departure of Manaus, he arrives at the most extreme point of this river in Brazilian territory; from there it advances to the village of Yavita, in Venezuelan lands. He had been in this small village for over a month, early in 1851, and there was something he might have never done before, and possibly never would have: a poetry. In it, he describes what he had been thinking and feeling in that quiet and distant region of the world considered as civilized.

\section{The Poetry}

Wallace states that the reason for his poetry at Yavita was "to pass the time during the boring nights"; also affirms to be "a poem in white verses, arranged in decassilabous by certain very poorly done, but that reflects positively my way of thinking, my state of mind in that moment".

Unlike the rest of the book, in which the texts were enlarged or corrected from their travel diaries, Wallace clarifies that the terms of his poetry were not altered in this work; that is, they were published in the same way in which they were originally conceived. The author says: "I transcribe them here, instead of giving a more sober and objective description, what I would certainly do if I were to describe it now, that some time has passed since I was there; I preferred to reproduce them ipsis litteris".

This Wallace text is not really poetry, because it lacks metrics or rhyme, but reveals something profoundly important in a work of this nature: freedom, lightness of soul, sincerity of settings; so the text is really poetic. Even more so, because the author himself considers it as poetry, something rare, perhaps non-existent, in other descriptions of him and also in the writings of the other naturalists who were in the Amazon in that century of lights.

In a state of mental exultation, Wallace speaks of his quietude in Yavita and of the revolt that nourished with certain aspects of the civilized life. He says verbatim: "although I have written them in a state of excited indignation against civilized life in general, a reaction which I presume to have arisen as a result of the monotonous life I was carrying there".

The first verses of poetry describe the murmuring brooks in the highlands and in the shade of the forest: some running toward the Orinoco blizzard and others toward the Negro and thence towards the Amazon. He considers this last river the "king of the rivers", for being the most powerful in the whole world and facing the mighty Ocean, making him 
withdraw from his dominions.

After this reverence for the Amazonian waters, Wallace speaks of him and of the natives with whom he was living; affirms that "it was the only white there and that all the two hundred inhabitants were Indians with copper skin, black hair, peaceful nature - semi-civilized and happy". He then narrates certain indigenous habits, influenced by the morality of the Spanish conquerors, how to keep the body, house, and square clean. In addition, the way to behave in the church: "everyone went to Mass on Sundays, in clean clothes and sat on the right and women on the left".

He speaks of the "long-braided girls who resembled the girls from the interior of England. However, the Indies were more graceful and better made, because they did not use the straps and bodices that hinder the free growth of bodies. "At some point in the text, he makes aesthetic recommendation, remembering that "simple food, baths and exercises: it is all that nature needs to form beautiful and healthy bodies".

Poetry also tells us that the Indians always have something to do: cut logs in the woods, harvest logs to make nets, weave baskets and fish with hooks, harpoons, bows and arrows. The women go to the field to plant and harvest cassava in the virgin land and not harmed by bars or plows; the young women search for water in pitchers they bring on their heads; "In the morning and evening hours, they will bathe in the sparkling waters; playing in gay bands, which mermaids."

He describes the villages, stating that they "are disposed with good taste: in the middle, the large square of the chapel and from which are drawn very narrow streets, ornamented with small houses, among which lie banana trees full of gold curls; orange trees, limeira and guava trees, coconuts of palm trees and inlayers of which hang flowers of which hummingbirds like ". Also describes the houses "with walls of mud and mud and on top white clay; palm leaf cover. There is not a single nail in the construction, the moorings are made with vines; however, it is all firm and secure enough to face storms and gales. "

Poetry tells of eating habits, stating that the Indians "eat simple foods such as fish, bread made from cassava, game meat, many fruits, birds, insects, eggs, turtles; they drink booze made from manioc juice, and everything is prepared with burnt peppers, sauces and condiments; from outside receive only the salt, exchanged for things that produce ".

He describes the lively festivals and in which "they are drenched with much caxiri or xirac, a drink made from the fermented cassava mass and very much like beer," but with the caliber of bandy. "After they take it, they become talkative, they laugh, they sing satisfied, they beat drums, they play ugly bamboo flutes. Men and women spin and dance tirelessly, which children, night in."

Poetry narrates in detail the manner of dressing and behaving of natives, especially of children: "Men wear tight clothing, but children walk naked; they have smooth and shiny skin and show themselves full of health and grace, running to the screams and pinotes; they face without fear the fastest currents! Sometimes, without a hat and a pin, they will crawl on the ground with a bow and arrow, a blowpipe, and they will go out in the forest or go fishing in the river."

Nostalgic of his homeland, Wallace makes slight comparisons between the lifestyles of Indian and English children, saying "feel sorry for the Englishmen restrained by uncomfortable clothes, with their feet imprisoned in boots that make their little fingers deformed, always keeping their heads, bent by the weight of hats; whole body weakened by this inconsequential luxury! But it's still the young English girls, whose panting experts squeeze themselves, from the thin belts in the vile and torturous corsets. "

Finally, Wallace traces the general profile of the natives in a natural state, saying that "such people live, simply in peace and love; they do not know the stupid vilanias, the stupid desires, the anguish and the thirst for gold and money of the man who calls himself civilized." At the same time, it shows the other side of the situation, that is, the non-possession of certain values of modern civilization, pleasures that only culture, art and reading can provide in a different world every day. Finally, he considers that this advantage of modern civilization does not have much foundation, because "there is also much inequality in the world of whites: on the one hand privileged, greedy for money and other sufferers and who has nothing and therefore can not receive the benefits linked to culture and art. "

Wallace concludes his poetic narrative by revealing his admiration and even preference for the simple, free, and healthy world of the natives as opposed to the complex, competitive, sickly world of whites: "I'd rather be Indian here than have to vegetate as one of those who live in the city, only think of money or live desolate and on the margins of society; I prefer to be Indian here before, living joyfully, fishing, walking, hunting and watching children grow, free as doves, with peace in mind and body with health; happy to have everything and be rich, even without a penny in his pocket. "

With this text, Wallace reveals many interesting facts about the nature and way of life of the Indians of the upper Rio 
Negro, but reveals in an exemplary way that knowledge can be constructed in many ways, including poetry. Unfortunately, something almost forbidden by modern science, usually versed in statistical calculations and in truncated, elitist and hermetic language.

\section{Return to Manaus}

After having spent more than a month in Yavita, Wallace leaves this town on March 31, 1851 and returns to Manaus, but first takes to climb up to the Jauaretê waterfall, in the middle course of the Uaupés, the main arm of the Negro and whose springs are located in Colombian territory. It is established in the vicinity of this waterfall for about a week and there it gives up of continuing until the Andes, its initial plan; on the contrary, he decided to return to Manaus to unload the canoe, to store the collected material and then to raise Uaupés again, since he considered this river "the best in the world to make a beautiful collection of birds and other animals."

Wallace was hurting the long distance between the descent to Barra and the new ascent to where he was, on a course that stretched for about 1500 miles, or nearly 2,500 kilometers between round and round; at that moment he confesses his homesickness, but he was determined to go up the river again. Thus, it began its descent until Manaus, having arrived there 15 days after leaving Saint Joaquim, at the mouth of Uaupés.

After so many months traveling inland and seeing so many dirty huts half hidden among the foliage along the rivers, Wallace says he is delighted with "the whitewashed houses and the excellent situation of the city of Barra." Here he disembarks and spends about two weeks preparing the material for the new ascent to Uaupés.

While in Barra, he met with his friend Richard Spruce who was also preparing a trip to climb the Rio Negro. Curiously, the house in which both were housed had already been inhabited by Johann Natterer and other travelers, hence it is regarded as the "official" residence of the European expeditionaries.

\section{Second Trip to the Rio Uaupés}

Wallace returned for the second time to Rio Negro in November 1851 to continue the exploration of the Uaupés River; this time came to a place called Mucura. On this trip there was not much news, but he recounts the enormous work in crossing more than 50 waterfalls, being some insurmountable and for that reason have to get around them loading canoe and load by terra firma.

On this trip that lasted about six months, Wallace collected many fish and birds not found on the first trip; in addition, he managed many indigenous artifacts and made many drawings of fish. On his return from the trip, he was again with his friend Spruce in the village of São Gabriel da Cachoeira and arrived in Manaus on May 15 of that year, and now this village had been elevated to the condition of Province of Amazonas.

\section{Return to England}

As soon as he arrived in Manaus, after the trip to the Uaupés River, Wallace worked about a month to collect, catalog, box and dispatch the collected material that included all kinds of animal, vegetable and indigenous artifacts. After having done so, he undertook his return trip to Belém, which lasted about two months and there began preparations for the trip to his home country. On July 12, 1852, he boarded the Helen ship, carrying along with him all the collected material, highlighting about 10,000 skins of birds, 30 live birds and many notes.

\section{Fire and Loss of Collections}

Three weeks later, more precisely on August 6,1852, the ship on which he was traveling caught fire and practically everything was destroyed. The crew was saved thanks to the lifeboats and the food and water they carried on board. After the loss of the ship, they wandered the sea for 10 days, until they were rescued by the boat Jordeson transporting wood from Cuba to London. On October 10, 1852, after 80 days since leaving the port of Pará, the salvage ship with its valiant crew and with the already consecrated Alfred Wallace arrives at the port of London.

Wallace reports in detail the destruction of the ship, especially the impact of smoke and fire at sea, but it does so without any sense of terror, revulsion or anguish. On the contrary, he treats the event with a certain naturalness and even resignation, but it does not fail to show some regret and nostalgia for everything he had collected and guarded with such zeal and fire destroyed. The description he makes of this fact is truly touching, even more so than he does as 
he still had the opportunity to meet again with all that he had lost.

"With what pleasure I had been contemplating each of the rare and curious insects that increased my collections! How many times - entirely taken by the fever - I crawled through the forest until I was rewarded with the meeting of a beautiful and unknown species! How many places - never traversed by other European feet - other than my own, I now remembered because of the very rare birds and insects they provided to enlarge my collections! How many days and weeks of boredom I have spent, having as sole motivation the cherished hope of returning home, bringing with me numerous and beautiful memories of that wilderness!"

"Every thing that I brought represented an evocation, a longing; not to mention the fact that it was a significant proof that I had not wasted my time and effort. In addition, how much joyful and profitable occupation all those collections brought to me during the next years!"

Wallace concluded this almost prayer of relief and consolation "in thinking that all this was lost, not a single sample left to illustrate the unknown lands I had passed through, or to bring to my mind the scenes of wild beauty I had once contemplated."

Wallace seemed to be caught up, trying to find the strength and motivation to continue his life as a traveler by stating that "it was no good at all to regret thinking about what might have happened; the best thing I would have to do was think about what would actually happen now, just minding the real circumstances that I would have to face from now on."

A year after his trip to the Amazon, this intrepid naturalist embarked on an even longer expedition, around 8 years, between 1854 and 1862 to the Malay Archipelago, where he carried out a monumental work on biogeography.

\section{Fish Study}

Wallace spent much of his time in the Amazon for the collection, illustration and preservation of fish. In the narrative of his journey, there are several passages that corroborate this fact; one of them is that almost every day he returned from the forest where he had been collecting insects, plants and other organisms, he spent the end of afternoons to illustrate and preserve the fish that his travel companions and the Indians of those places brought him.

He mentions several times his admiration for the great diversity of the Rio Negro's ichthyofauna when he states that "during all the time I stayed in the Rio Negro, I tried to draw and describe all the species of fish I encountered; for well: even on the eve of my return, daily copies were brought to me entirely new to me".

Another striking fact is that he was continually surprised by the variation of the composition of the ichthyofauna in different rivers; not only among those of large and small, but also between rivers of black and white water. In particular, he admired the differences of the ichthyofauna even between stretches of the same river.

These facts are interesting, not only for themselves and in the context of the Amazonian ichthyofauna, but for them to be the first theoretical framework of the great ideas of this naturalist on the distribution of organisms in different regions of the world. It was on this basis that Wallace became one of the most respectable biogeographers of all time. The name "Wallace Line", given the border that separates the zoogeographic regions of Asia and Australasia is a clear realization of this.

The fish collected and preserved with so much effort and care were destroyed by the fire that consumed the boat in which Wallace returned to his homeland; however, his illustrations remained, stored in a special case and saved in the last minutes when he remained on the ship already on fire.

Most of Wallace's illustrations, made in pencil on paper were published by Monica de Toledo-Piza Ragazo, in a beautiful edition of Uspiana Brasil 500 years. This author presents 212 illustrations and reveals that they were accompanied by notes on the common name and size of the fish, as well as the location of their collection and various taxonomic data, such as the number of rays of the fins. This material is important not only to reveal the identity of the species, but also to show an interesting facet of this naturalist's talent: he was a keen observer and a good draftsman.

According to Ragazo, all this material was guarded by Wallace for more than fifty years; in 1904 he wrote to George Albert Boulenger, a curator of reptiles and fish at the British Museum of Natural History, asking whether this institution would be interested in harboring the collection of the 212 fish engravings he had made throughout his expedition through the Black River Basin; the proposal was accepted and the material was received by the Museum. A year later, another curator, Charles Tate Regan, published a list identifying 115 species of those illustrations.

The species name given by Regan was noted on the lower edge of the picture of each illustration, but curiously they 
were not reproduced in his article, because he considered the possibility of being species not yet described and that should deserve a different treatment. It was only in 2005, exactly one century after this Reginean note, that Wallace's illustrations were actually published in Ragazzo's book, cited above.

In this work, the author identifies 180 of the fish species, a smaller number than the illustrations, because the specimens of the same species have been illustrated more than once. However, there have been cases in which the illustration did not allow a safe identification and this is not only due to defect or omission of certain characteristics, but perhaps because it is a new species, not yet known scientifically. Such a possibility was confirmed in 2015 by Kullander, S. O and Varella, H.R. who described Crenicichla monicae as a new species based on those illustrations.

Other authors quoting Wallace's illustrations were Toledo-Piza, M; Menezes, N.A \& Santos, G.M in the description of Hydrolycus wallacei as a new species. More than this, these authors named this new species in honor of this illustrious naturalist.

Wallace had identified 205 species of fish on the Rio Negro, but estimated for this river a much higher number, around 500 or 600 species. Goulding, Carvalho \& Ferreira (1988) show an even larger number, about 700 species. Work in progress by Efrem Ferreira and collaborators (personal communication) indicate that the Rio Negro basin contains about 1,700 species, that is, more than a thousand species than those foreseen by Wallace; in this case, Negro would become the river with the richest ichthyofauna in the world, although its fish production is very low in Amazonian terms.

Of course, the importance of the ichthyofauna of the Rio Negro is not in the simple number of species, but in its high index of endemism, that is, species that only occur in this watershed. Likewise, the beauty of shapes and colors presented by the fish of this river, considered the paradise of ornamental fish. In some medium-sized cities, such as Barcelos and Santa Izabel, the economy revolves around the trade in live fish, especially the cardinal-tetra (Paracheirodon axelrodi); neon-tetra (P. innesi); neon-green (P. simulans); rodostomus (Hemigrammus rhodostomus, H. bleheri and Petitella georgiae) and blue discus (Symphysodon aequifasciatus) and red discus (S. discus).

Also important in this river is the sport fishing of the tucunare (Cichla monoculus, C. temensis) that every year, especially in the dry season, attracts fishermen from all over the world. Subsistence fishing is another fundamental issue, because although the abundance is small, fish is the main food resource for the thousands of residents living along the river and its tributaries hidden inside the dense Amazonian forest.

\section{Strategic Overview of Health and Food Production}

While traveling through the Negro and Uaupés rivers, without any hurry and being able to appreciate the potential of the region and the life style of its inhabitants, Wallace ended up making some interesting reflections that even today, more than a century and a half later, can be considered most up-to-date. In particular, the reflections presented regarding the health sector and food production.

The reflection about health was raised by the encounter that he had with a patient of malaria, afflicted by bouts of vomiting and dysentery and receiving totally inadequate treatment. Thus when the fever came, the sick man was forbidden to take refreshment, which was regarded as true poison to the sick; instead, they used to serve hot broths, cachaça and pepper, believing that this was a real remedy. Wallace intervened in this procedure, using the previously prohibited soft drink, besides cold baths, purgantes and application of quinine in the intervals of the accesses; in a few days the sick man healed, with surprise of him and of all who were there.

Wallace was also a victim of malaria and other illnesses while traveling, even infestation by footworts and infection from which he faced, and he knew well how much health is important for people living in a region so isolated from the Amazon. For him, the best way to contribute to health would be good nutrition, which would imply in the production of food.

The food challenge in the Rio Negro valley was well analyzed by Wallace when she compared the widespread lack of food with the abundant resources available in the forest and the agricultural potential of the region. He fancied the possibility of this region producing almost everything he needed, with just a little guidance and common sense.

Among the natural products that he suggests the possibility of being cultivated are vegetables, such as beans; grains such as corn and rice; tubers, such as cassava; fruits such as orange, pineapple and watermelon; besides molasses, sugar; cattle, goats and pigs.

Still referring to the possibility and even the need for autochthonous food production in the Rio Negro valley, Wallace asserts that "supposing that they adapt to the diet of corn husks and cassava bean, nothing else will be bought by the 
residents, except clothes and cloths; the food will gradually remain: pork, beef and mutton; poultry and eggs; butter, milk and cheeses; coffee and cocoa; molasses, sugar and rapadura; delicious fish; turtles and their eggs; variety of game meat; all this to provide them with a table with constantly renewed varieties. In addition, it mentions the potential represented by wild fruits and palm trees that can be used to produce oil, olive oil and all types of beverages.

Wallace seemed genuinely excited about the potential of this region and even commented on the possibility of using native plants, such as palm trees, to be used in gardens and alleys in the cities and even the properties' paths; also the possibility of building orchid beds under the trees that surround the villages and even the houses of the interior. It concludes the description of these gardens, remembering the possibility of using several climbing plants in the walls walls of the house and with which one could also build beautiful and pleasant arbors.

While reflecting on these potentialities and beauties of the Black River valley, Wallace turned his thoughts back to his native country and, with a moving expression, said: "England! My heart belongs to you! Hometown I love so much! However, "the prospect of the wonderful life that would await me here, free from the financial worries and annoyances of civilization, makes me hesitate to return to your fields or bid you farewell forever, to enjoy here in this Black River a life full of tranquility, plenty and peace."

\section{Life Lessons}

Alfred Wallace had a very intense life, marked by great adventures in lands distant and unknown and also by revolutionary theories in the field of science. In a sense, it can be said that he had a life marked by a virtuosity that deserves to be widely shown and debated, especially in the academic sector. I would like to highlight some positive aspects of the life of this eminent person, which should be an edifying example and inspiration, especially for young naturalists and scientists.

\section{Courage and Determination}

It is striking to note that at the age of twenty-five Wallace has determined to take on such a complex and risky mission to leave his country to venture into a distant region unknown not only to him but to all, even the administrators and responsible for that region; in fact, no maps existed.

Interestingly, Wallace was one of the first to draw the outline of the Black River basin. Wallace was accompanied by his friend Henri Bates and he was even younger, he was only 23 years old. In this sense, it seems that the joining of the youth gave strength and doubled courage to the pair. It is important to note that other naturalistic travelers of the same carat, such as Alexander von Humboldt and Ermanno Stradelli, also undertook trips to the South American continent with the same age group.

Wallace knew of the discomfort of the tropical region, with its excess of sun, rain, and humidity; knew of the threats of vermin, termites, mosquitoes, ticks, and ticks; knew of the dangers of common diseases in the region, such as dysentery and malaria, and the dangers of an accident inside the forest and the crossing of waterfalls, but at no time showed excitement or fear; on the contrary, faced all these problems with courage and high spirit.

Wallace had tremendous intellectual courage and impressive determination; seemed taken not only by a messianic mission of natural history, but by an immortal dream. This was the main reason for the success of his enterprise, even in spite of the destruction of its collections by the fire of the ship that took them from Brazil to England.

\section{Dedication to Study and Work}

Wallace was born and raised to adulthood in a modest family; he was the eighth in the class of ten brothers and had to work early to support himself economically. Around 1835, his father Thomas Wallace was evicted from his property and the family went through difficult times; in early 1837 the boy Alfred, at the age of 14, had to leave school and went to London to live with his older brother, John, who worked in the surveying sector; in the middle of the same year he leaves London and goes to Bedfordshire to work with William, the eldest of the family and who owned a small surveying company

While working as an apprentice to his brother, he also attended classes and eagerly read matters relating to mechanics and natural history; it was at this time that he maintained contact with social reformist leaders and ideas. A few years later he went to work with William, another brother, owner of a Land Survey firm in London, and stayed there for about six years. It was as an apprentice and later as a professional of surveying that he obtained the first experiences and, above all, the taste for the landscapes and the elements of nature.

In 1843, after six years of working with his brother in rural South England and Wales, he applied for a position at 
Collegiate School in Leicester and was hired to teach drawing, surveying, English and arithmetic classes. Moving from field to school was a fair and elegant way for him to pass on to young students what he had learned a little earlier.

While teaching, Wallace took the time to study important works in the Leicester library and had access to works that were instrumental in his future as a naturalist, such as Thomas Malthus's "an essay on the principle of population. It was probably there that he met the young entomologist Henry Walter Bates, his future traveling companion to the Brazilian Amazon and with whom he learned to become familiar with insects.

Some time later, around 1845, Wallace was hired as a civil engineer at a firm that had been responsible for surveying the land for the construction of a railroad in the Neath valley; this craft also allowed him to spend a lot of time outdoors in the field, a fact that activated his involvement with the insects even more. Shortly afterwards, together with his brother John, he set up a construction firm and was entrusted with various projects, including the construction of the Institute of Mechanics building, where he was hired as a professor of engineering and science. Here, too, he wanted fate that he share with the younger ones the craft he had learned.

In 1846, at the age of twenty-three, he and his brother John acquired a cottage in Neath's neighborhood and lived there in the company of their mother and sister since their father had died about three years earlier. It was in this quiet environment that he exchanged innumerable letters with his friend Bates, commenting on the ideas and adventures quoted in the works of Alexander Von Humboldt (Kosmos), Robert Chambers (Vestiges of the natural history of creation); the Voyage up the river Amazon (William Henry Edward), Beagle Trip (Charles Darwin).

These works were fundamental and even decisive for him to decide in 1847, together with Henri Bates, to undertake the famous expedition to the Brazilian Amazon. There he remained from 1848 to 1852. In a report he made a year after this expedition, he shows easily that he spent four years working uninterruptedly, even when he was ill or facing terrible obstacles in the jungle and the rivers he passed through. The same dedication to the work he demonstrates when he returns to England and spend about a year collecting data from his journals and publishes the narrative of his trip to Brazil in the monumental work "Travels through Solimões and Negro rivers."

Perhaps even more surprising is the expedition he undertook for eight years between 1854 and 1862 in the Malay Archipelago - a name given at that time to present-day Indonesia, New Guinea, and Malaysia. It was on this continent that Wallace formulated the principle of natural selection theory and made other discoveries in biology, geology, geography, and ethnography. In this "end-of-the-world" Wallace worked hard and faced as many or more obstacles as those found in the Amazon. During his stay in the archipelago, he published the book "Journey to the Malayan Archipelago" and made the revolutionary theory about the origin of the species and was crowned with the joint publication with Charles Darwin in 1858 by the Linnean Society of London.

These facts are illustrative and serve to show that Wallace was a great entrepreneur, who devoted himself to the work and learned and taught with him. In fact, he lived working and made it the aesthetic of his existence.

\section{Admiration and Respect for Diversity}

Biological and cultural diversity was the major motivation for Wallace's major ventures. As a young man, at age 14, he was already interested in the political ideas that led to social reformers; in his trips through the Amazon and the Malayan archipelago, has always been enchanted by the diversity of forms, colors and patterns of distribution of animals and plants; always showed understandable and friendly in dealing with local residents and in addition, extremely interested in their cultural and artistic expressions.

Much of the narrative he wrote about his trip to the Amazon is dedicated to Indian customs and it is easy to see how he was enchanted by the beauty of insects and birds, even creating several of them inside the makeshift boat in which he traveled; even embarked several parrots, toucans and monkeys on the boat that would take him back to England and deeply hurt that they had perished in the fire that consumed the ship at sea.

Wallace was also impressively tolerant when he had canoe, brandy and other items stolen by the crew, and also when people hired and paid to row and carry loads were stolen from attending the service. Although he has described several of these episodes in his book, he has at no time mocked or tried to disparage those people because of these naturally incorrect attitudes in any kind of civilization.

For Wallace, diversity was not only manifestation, but the very essence and reason of life; it was from the observation of the latent diversity in all the localities that he saw that he had the idea that the species originated and diversified in the own land, without need of divine plan for its creation and diversification. More than that: it is the very diversity that conditions evolution; after all, it is in her that come the weakest that perish and the strong that prosper. That is, diversity is the result and also the origin of all life forms. Not only did Wallace conceive this genial idea, later shared with his 
colleague Charles Darwin, but he was charmed by it; for him, the diversity of life was something magical and worthy of all respect and admiration.

\section{Humility and Tolerance}

Every good scientist, truly interested in the truth, is naturally humble; In this sense, humility presupposes not only admiration and respect for diversity, but also submission to its principles.

Wallace was an extremely humble person; nothing better to justify this than his serene attitude to the historical fact of his pioneering work on the origin of the species "on the tendency of varieties indefinitely from the original type" was published in co-authorship of Charles Darwin, by decision of the authorities of the Linnean Society of London.

In fact, this unilateral decision took him the opportunity to be the first and perhaps the greatest protagonist in evolution theory, which was conferred on Darwin by his famous book Origin of Species, but based on that episode. In any case, instead of feeling wronged or offended, Wallace was pleased and even honored that the authorship of his article was shared with his admirable Darwin.

Wallace's humility to be part of the select group of English naturalists can be seen in his words to Darwin, shortly after the publication of his famous book on the origin of species: "as for the theory of natural selection itself, as if it were really yours and only yours. You worked it out in detail (which I never thought of) years before I had a ray of light on the subject, and my article would never have convinced anyone or would be seen only as an ingenious speculation while your book revolutionized the study of natural history; all the merit that I claim is the relevance of having induced you to write and publish immediately. "

Another notable fact that attests to Wallace's humility was his idea that the development of the human spirit was the main reason for the existence of the universe. True, this conception is opposed to the purely materialist idea of evolution espoused by his colleague Darwin, but shows how much Wallace was influenced by the aspects of subjectivity and human spirituality, still today the greatest mystery that science still faces and still remains almost entirely covered by mysteries.

Wallace's humility was so clear and convincing that, at his suggestion and later endorsed by his wife, his body was buried in the small cemetery at Broadstone Dorset and not at the fabulous Werstminster Abbey, where his body is found.

\section{Scientific Spirit and Spirituality}

Wallace did not have an advanced academic background. In 1828, when he was only five, his family moved to the small town of Hertford and then joined the Hertford Grammar School, where he received his only formal education. At age 14 she had to drop out of school and continue to learn in life. Maybe that's why he was a talented and creative self-taught; he was able to conceive innovative ideas and to work essentially scientifically with the animals, the plants and other elements of the nature, he explored in the collection and preservation of copies destined to the museums and demanding collectors of Europe.

Even with the difficulties of the countryside and the precariousness of the infrastructure available for his work, he made spectacular collections; drew minute maps; made exquisite designs and wrote numerous books and scientific articles. That is, Wallace was not a scientist trained in the academy's classrooms, but on journeys through seas, woods and rivers. He possessed an authentic scientific spirit and genuine spirituality, something essential for anyone and anyone interested in science, research and knowledge as a whole.

\section{Classification of the Waters of the Amazon}

Wallace was the first researcher to classify the Amazonian waters in terms of color and apparent transparency. He is the proponent of the still current picture on the main types of waters, that is, white (coming from the foothills of the Andes, such as the river Solimões-Amazonas, Purus and Madeira); Clears (coming from the shields of Central Brazil, such as the Tocantins and Xingu rivers) and blacks (from sandy lands with open grassland, such as the Rio Negro).

In the last decades, several authors such as Herald Sioli and Wolfgang Jung have confirmed this classification, adding new physical and biochemical parameters such as $\mathrm{pH}$, conductivity and concentration of certain elements such as calcium and phosphorus. Lately, post-graduates and even renowned researchers have to refer to this same classification, without due credit to Wallace. Unfortunately, most journals and even scientific institutions have been demanding that bibliographical citations be made about recent or current works, to the detriment of the older ones. However, this is unfair and incorrect. In the specific case of the classification of the Amazonian waters, the name of Wallace should not be despised and much less forgotten. Still more correctly and fairly, the name of this important naturalist must always be remembered for the many other information he has collected and published about the immense and fascinating 
Amazonian world.

\section{Conclusion}

This brief review of Alfred Wallace's expedition to the Amazon and also about some aspects of his life intends to show that he was a person totally dedicated to work and science; faced all kinds of challenges, but was determined and persistent and ended up winning. In this sense, it is an exemplary figure for all, especially for young scientists Many believe that he was wronged by the Academy and despised by history; nevertheless, the Academy is continually renewed and history serves just that: to rescue facts and to do justice in due time.

\section{References}

Cohen, B. (1985). Revolution in science. Cambridge: Harvard University Press.

Goulding, M., Carvalho, M. L., \& Ferreira, E. J. G. (1988). Rio Negro - rich life in poor water. SPB. Academic Publising: The Hague.

Junk, W. J., Ohly, J. J., Piedade, M. T. F., \& Soares, M. G. M. (eds). (2000). The Central Amazon Floodplain: actual use and options for a sustainable management. Bachhuys Publ., Leiden: The Nterlands.

Kullander, S. O., \& Varella, H. R. (2015). Wallace's pike cichlid gets a name after 160 Years: a new species of cichlid fish (Teleostei: Cichlidae) from the upper Rio Negro in Brazil. Copeia, 103(3), 512-519. https://doi.org/10.1643/CI-14-169

Ragazzo, M. T. P. (2002). Peixes do rio Negro - Alfred Russel Wallace (1850-1852). Edusp: Imprensa Oficial SP.

Sioli, H. (1968). Hydrochemistry and geology in the Brazilian Amazon region. Amazoniana, 1(3), 267-277.

Sioli, H. (1967). Studies in Amazonian waters. Atas do Simpósio sobre a Biota Amazônica, 3, 9-50.

Toledo-Piza, M. (1999). Revision of the neotropical fish genus Hydrolycus (Ostariophysi: Cynodontinae) with the description of two new species. Ichthyol. Explor. Freshwaters, 10(3), 255-280.

Wallace, A. R. (1889). A narrative of travels on the Amazon and Rio Negro. London, Lock \& Co. 